\title{
Dynamical downscaling of rainfall and temperature over the Arabian Peninsula using RegCM4
}

\author{
Mansour Almazroui* \\ Center of Excellence for Climate Change Research/Department of Meteorology, King Abdulaziz University, PO Box 80234, \\ Jeddah 21589, Saudi Arabia
}

\begin{abstract}
We use the International Centre for Theoretical Physics' (ICTP) regional climate model (RegCM4) nested in the European Community-Hamburg atmospheric model (ECHAM5) and the European Centre for Medium-Range Weather Forecasts' (ECMWF) 40-yr reanalysis (ERA40) data to perform and analyze multi-decadal present-day climate simulation over the Arabian Peninsula. Mean climatology, annual cycle, and interannual variability of rainfall and temperature are compared to observational data. The results show that, while ECHAM5 and ERA40 exhibit drier and warmer biases, RegCM4 simulates higher rainfall intensity and lower warm temperatures, providing a more realistic spatial distribution of these variables over the region. This originates from a more reasonable simulation of specific humidity, wind fields, and geopotential heights compared to the driving field. Annual cycles over the northern Arabian Peninsula (NAP) are better captured by RegCM4 than by ECHAM5, while, over the south (SAP), annual cycles mostly follow the driving field. This suggests that the annual cycle over the NAP is driven by regional processes represented by the internal regional climate model dynamics and physics, and, over the SAP sub-region, the influences of large-scale conditions induced by boundary forcing are dominant. Both RegCM4 and ECHAM5 exhibit similar performance in terms of variance over the low-variability region (SAP); however, the regional climate model outperforms the driving global climate model for the high-variability region (NAP). Therefore, although dynamical downscaling offers some improvements regarding climatology and the annual cycle, it has mixed benefits in terms of interannual variability.
\end{abstract}

KEY WORDS: Dynamical downscaling - Global climate model - Climatology · Annual cycle · Interannual variability $\cdot$ Saudi Arabia $\cdot$ Arabian Peninsula

\section{INTRODUCTION}

Understanding and predicting climate change is a major concern for the research community because of its adverse effects on the socio-economic and environmental aspects of human activities (Parry et al. 2007). Providing reliable information to the diverse communities involved in these issues, especially policy and decision makers, is therefore of critical importance.

Such information is often derived from coupled atmospheric-ocean global climate models (AOGCMs), supplying valuable estimates of both natural and anthropogenic climate changes and variability on global scales (Meehl et al. 2007). However, the outputs are limited in their use for many smaller scale applications because of their coarse horizontal resolution; they are unable to resolve regional features such as coastlines, steep topography, and vegetation gradients, all of which play a major role in determining the climatic characteristics of a region. To obtain climate change information at local and regional levels (critical for impact assessments) and to account for land-surface heterogeneity at the same time, AOGCM outputs need to be downscaled to a higher resolution (Christensen et al. 2007). 
Dynamical downscaling is based on the application of a regional climate model (RCM), deriving highresolution information for a selected domain (that covers the particular region of interest) by employing an AOGCM and/or reanalysis data at the lateral boundaries (Giorgi \& Mearns 1999). RCMs are extensively used in a wide variety of applications concerning regional climate change (e.g. Giorgi et al. 2004, Diffenbaugh et al. 2005, Im et al. 2007, Pal et al. 2007), regional climate processes (e.g. Pal \& Eltahir 2003, Gao et al. 2007), and seasonal climate variability (e.g. Rauscher et al. 2006, Seth et al. 2007). While most of these studies have been concentrated on regions in Europe, America, Asia, and Africa, some previous studies have also included domains encompassing part of the Arabian Peninsula (Evans et al. 2004, Zakey et al. 2006, Chenoweth et al. 2011, Güttler 2011, Krichak et al. 2011, Smiatek et al. 2011), but only a few have focused on the entire Arabian Peninsula and adjacent Indian Ocean. Almazroui (2011a) performed several case studies to investigate the impact of different domain sizes, resolution, and reanalysis boundary forcings on the RCM simulation of 2 high-intensity rainfall events over Saudi Arabia, and Marcella \& Eltahir (2012) examined the role of land-surface processes in shaping the regional climate of the Arabian Peninsula's semi-arid regions. While most of these experiments are process studies, no previous research has dealt with the potential or added value of using an RCM to downscale AOGCM outputs in the context of a climate change study for the entire Arabian Peninsula.

Climate change is a key factor in the socioeconomic development of this region because of its semi-arid to arid nature; rainfall is low, and temperature is high (Abdullah \& Almazroui 1998). These exert a strong influence on application-oriented sectors such as agriculture, water resources, and power generation (Islam 2009, Almazroui 2011b). Therefore, downscaling AOGCM outputs may help to better assess the regional climate. However, before applying an RCM to climate change studies for a particular region, the accuracy of the model to successfully reproduce the observed regional climate characteristics should be assessed in order to improve the forcing AOGCM simulation. The model's performance needs to be evaluated in order to establish whether the RCM enhances the simulation of present-day climate when compared to the AOGCM (Giorgi \& Mearns 1999).

To this end, we analyze 2 sets of experiments performed over the Arabian Peninsula by nesting the latest version of the Abdus Salam International Cen- tre for Theoretical Physics' (ICTP) regional climate model (RegCM4; Giorgi et al. 2012) within both the European Centre for Medium-Range Weather Forecast's (ECMWF) 40 yr reanalysis (ERA40; Uppala et al. 2005) and the European Community-Hamburg atmospheric model (ECHAM5; Roeckner et al. 2003) coupled to the Max Planck Institute ocean model (MPIOM; Jungclaus et al. 2006). Particular interest is focused on comparing the RegCM4 output driven by ECHAM5, with the latter being used to evaluate the extent to which the RCM improves simulation of the AOGCM over the Arabian Peninsula. We focus not only on climatology but also on the annual cycle and variance representing the overall year-to-year variability. This assessment, prior to any generation of reliable climate change scenarios, is critical for a better interpretation of the projections over the region.

\section{DATA AND ANALYSIS METHODOLOGY}

The latest version of the RCM recently released by the ICTP, namely RegCM4, is adopted in the present study (Giorgi et al. 2012, this Special). RegCM4 is a primitive equation model, compressible, and solved on sigma vertical coordinates. It employs the dynamical core of MM5 and incorporates multiple physical schemes, including those of Kiehl et al. (1996) for radiation, Dickinson et al. (1993) for land-surface processes, Holtslag et al. (1990) for the planetary boundary layer, and Zeng et al. (1998) for ocean flux parameterization. Large-scale (grid-resolvable scale) precipitation processes are treated using the sub-grid explicit moisture scheme (SUBEX) of Pal et al. (2000). For convective precipitation, RegCM4 includes 3 options: the Kuo-type scheme of Anthes (1977) in its simplified implementation as described by Grell et al. (1994) and the schemes of Emanuel (1991) and Grell et al. (1994). Based on a previous study over the region (Almazroui 2011a) and on number of tests of this model, we employ the scheme of Grell et al. (1994), using the closure assumption based on Fritsch \& Chappell (1980).

Two simulations are conducted over a domain $\left(0-45^{\circ} \mathrm{N}, 15-75^{\circ} \mathrm{E}\right)$ encompassing the entire Arabian Peninsula and surrounding lands and oceans (Fig. 1). Note that Fig. 1 shows the interior domain after removal of the buffer zone. For the first simulation, the initial and lateral boundary conditions are created using the ECMWF's ERA40 data (Uppala et al. $2005)$, with a grid spacing of $2.5^{\circ} \times 2.5^{\circ}$ interpolated onto the RegCM4 resolution, hereafter referred to as ERA40. The second experiment is forced by the 

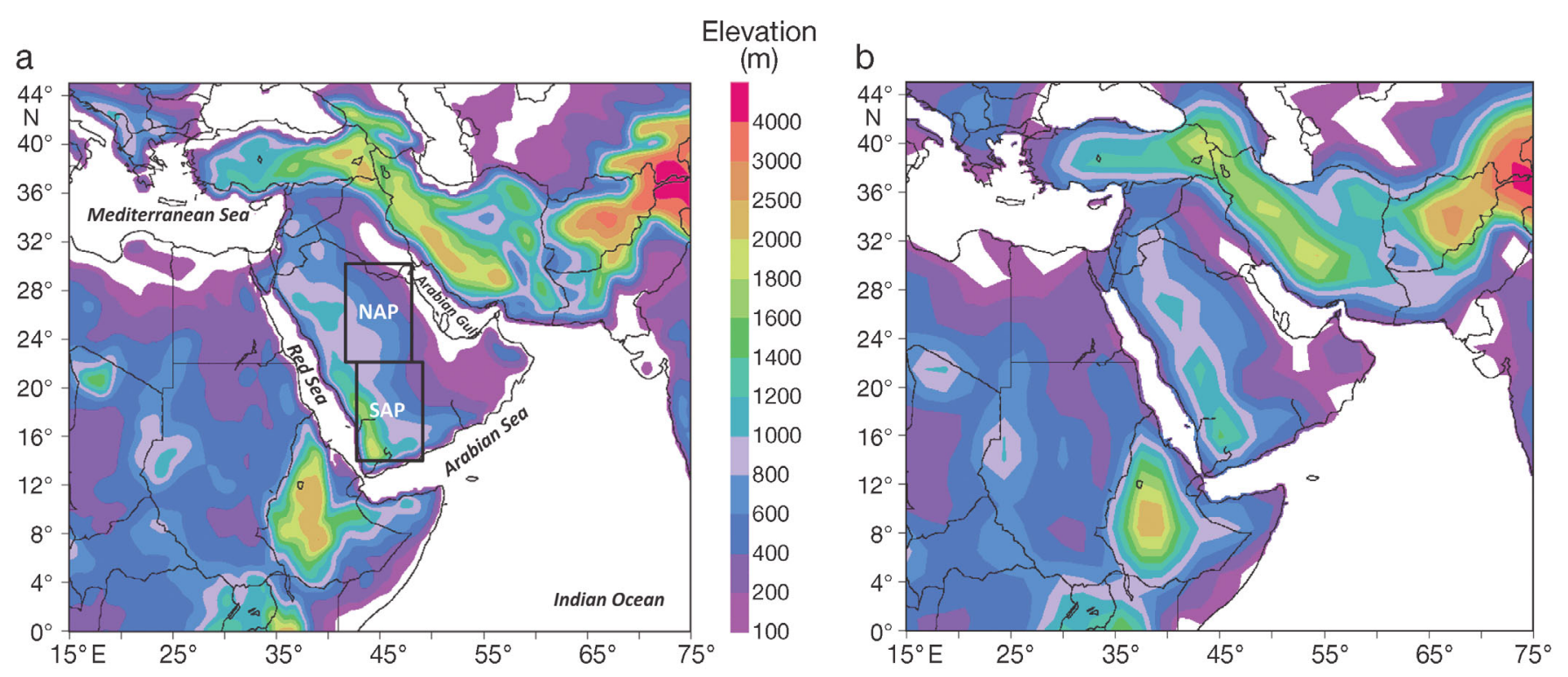

Fig. 1. (a) Analysis domain and RegCM4 topography and (b) ECHAM5 topography. Sub-regions: northern (NAP) and southern Arabian Peninsula (SAP)

ECHAM5 (Roeckner et al. 2003) coupled with the MPIOM (Jungclaus et al. 2006), hereafter referred to as ECHAM5. ECHAM5 has a spectral resolution of T63 $\left(\sim 1.8^{\circ} \times 1.8^{\circ}\right)$ interpolated onto the RegCM4 grid. Over the Indian Ocean, the prescribed sea-surface temperatures (SSTs) for the ERA40-driven run are acquired from the NOAA Optimum Interpolation SST $\left(1^{\circ} \times 1^{\circ}\right.$ resolution) weekly analysis (Version 2; Reynolds et al. 2002). The ECHAM5-driven run uses SST produced by the MPIOM. The topography and land-use data were, respectively, obtained from the United States Geological Survey (USGS) and the Global Land Cover Characterization (GLCC) (Loveland et al. 2000).

The 2 continuous simulations (ERA40-RegCM4 and ECHAM5-RegCM4) are performed using a resolution of $50 \mathrm{~km}$ and 18 sigma vertical levels for the $23 \mathrm{yr}$ present-day climate, from January 1978 through December 2000, employing, respectively, ERA40 and ECHAM5 at the lateral boundaries. Note that only $22 \mathrm{yr}$ are taken into account; the first year (1978) is discarded as spin-up time. We analyze the climatology, the annual cycle, and the interannual variability of rainfall and temperature, based on annually averaged values. The results from both experiments are compared to the observed precipitation and temperature, at a resolution of $0.5^{\circ} \times 0.5^{\circ}$, taken from the Climatic Research Unit (CRU; Mitchell et al. 2004) in order to determine the bias of each simulation. The GPCP (Global Precipitation Climatology Project, $2.5^{\circ} \times 2.5^{\circ}$ resolution; Adler et al. 2003) is also used for validation purposes for rainfall over the surrounding bodies of water, and to account for uncertainties that are often present in precipitation observations. We include in the analysis the rainfall and temperature fields from the driving data (ERA40 and ECHAM5) to discuss the added and/or retained value and to investigate the extent to which RegCM4 is able to reduce, increase, or maintain the gap for both the spatial extension and the magnitude of the 2 boundary forcings. This performance is further examined by computing certain statistics such as mean bias, root mean square error, and correlation coefficients (see Table 1). The circulation features are compared with both driving large-scale datasets (i.e. of ERA40 and ECHAM5). Finally, the temporal variability (annual cycle and interannual variability) of the simulated rainfall and temperature are analyzed over 2 homogeneous sub-regions (in Fig. 1), the northern Arabian Peninsula (NAP) and southern Arabian Peninsula (SAP), as they are 2 different climatic sub-regions with different characteristics. In fact, the NAP sub-region is mainly low-elevation terrain, while the SAP incorporates more complex terrain. In addition, the NAP climate is mainly influenced by mid-latitude circulations, while the SAP climate is mainly influenced by south-westerly monsoons (Chakraborty et al. 2006), where local topography plays a role in enhancing convective systems (Abdullah \& Al-Mazroui 1998). This drives a doublepeaked rainy season over the SAP and a unimodal annual cycle over the NAP (e.g. Almazroui 2011b). 


\section{RESULTS}

\subsection{Mean climatology of precipitation and temperature}

For the evaluation of model performance, we consider the patterns of the spatial distribution of annual rainfall and temperature averaged for the period 1979-2000. Fig. 2a-f shows the spatial distributions of rainfall climatology for CRU and GPCP observations, the 2 driving fields of ERA40 and ECHAM5, and the 2 simulations (ERA40-RegCM4 and ECHAM5-RegCM4). Fig. 3a-f presents the respective biases with respect to CRU, along with the differences between the 2 boundary forcings and between the 2 simulations. Table 1 displays the regional mean bias and the root mean square errors over the NAP and SAP sub-regions.

The observations exhibit the highest rainfall over the complex terrains adjacent to the Red Sea and also in the central and northern Arabian Peninsula. The

Table 1. Bias, root mean square error (RMSE) and correlation coefficients for rainfall $(\%)$ and temperature $\left({ }^{\circ} \mathrm{C}\right)$ with respect to data from the Climate Research Unit (CRU) averaged over 1979-2000 for the northern (NAP) and southern Arabian Peninsula (SAP) sub-regions. Rainfall expressed as a percentage of CRU values. ERA40: European Centre for Medium-Range Weather Forecasts' 40-yr reanalysis data; ECHAM5: European Community-Hamburg atmospheric model; RegCM4: regional climate model nested in the ECHAM5

\begin{tabular}{|c|c|c|c|c|}
\hline & \multirow[t]{2}{*}{ ERA40 } & \multirow[t]{2}{*}{ ECHAM5 } & \multicolumn{2}{|c|}{- RegCM4 } \\
\hline & & & ERA40 & ECHAM5 \\
\hline \multicolumn{5}{|l|}{ Bias } \\
\hline \multicolumn{5}{|c|}{ Rainfall } \\
\hline NAP & -73.01 & -77.31 & 64.83 & 4.29 \\
\hline SAP & -68.19 & -35.44 & 23.16 & -17.78 \\
\hline \multicolumn{5}{|c|}{ Temperature } \\
\hline NAP & 4.84 & 4.42 & 0.45 & 0.42 \\
\hline SAP & 7.40 & 6.48 & 3.92 & 3.73 \\
\hline \multicolumn{5}{|l|}{ RMSE } \\
\hline \multicolumn{5}{|c|}{ Rainfall } \\
\hline NAP & 0.17 & 0.18 & 0.17 & 0.11 \\
\hline SAP & 0.34 & 0.36 & 0.52 & 0.41 \\
\hline \multicolumn{5}{|c|}{ Temperature } \\
\hline NAP & 4.08 & 3.66 & 1.49 & 1.50 \\
\hline SAP & 6.62 & 5.84 & 4.26 & 4.11 \\
\hline \multicolumn{5}{|c|}{ Correlation coefficient } \\
\hline \multicolumn{5}{|c|}{ Rainfall } \\
\hline NAP & 0.73 & 0.63 & 0.92 & 0.84 \\
\hline SAP & 0.69 & 0.13 & 0.61 & 0.16 \\
\hline \multicolumn{5}{|c|}{ Temperature } \\
\hline NAP & 0.999 & 0.996 & 0.997 & 0.996 \\
\hline SAP & 0.996 & 0.984 & 0.984 & 0.992 \\
\hline
\end{tabular}

rainfall intensity decreases southeastwards, and the regions closer to the Arabian Sea experience less rainfall (Fig. 2a,b). It is worth noting that there are considerable differences among these observed gridded datasets in terms of magnitude and the spatial extent of mean rainfall. For instance, CRU has a tendency to show sharper and steeper maxima following the topography; this is missing in the GPCP, which exhibits smoother rainfall patterns over the southwestern region of the peninsula. The ERA40 and ECHAM5 confine the rainfall to the southern regions near the Gulf of Aden and markedly underestimate the intensity all over the peninsula. The ERA40RegCM4 and ECHAM5-RegCM4 reproduce the rainfall patterns well. In particular, ECHAM5-RegCM4 captures the maximum over the mountain range in the southwest, the southeastward reduction of rainfall, and the lower intensity over the coastal regions adjacent to the Arabian Sea remarkably well and, therefore, appears to be very close to the CRU climatology. The forcing fields and simulations exhibit different bias patterns. ERA40 and ECHAM5 substantially and consistently underestimate the rainfall over the entire peninsula, by up to $100 \%$. However, the ECHAM5 magnitude appears to be generally larger than that in ERA40, mostly along the regions adjacent to the Red Sea, by $>100 \%$ (Fig. 3e). In contrast to ERA40, ERA40-RegCM4 produces wet bias almost everywhere over the peninsula, except along the mountainous regions adjacent to the Red and Arabian Seas, which experience dry bias. ECHAM5-RegCM4 extends this dry bias inland and notably reduces the wet bias over the peninsula, resulting in a rainfall intensity that was about $40-60 \%$ weaker compared to ERA40-RegCM4. The decrease in rainfall bias evident in the RegCM4 simulations, compared to ECHAM5, is confirmed in Table 1, showing, respectively, the regional bias and root mean square error for the 2 sub-regions: NAP and SAP. Over both subregions, the regional bias is generally smaller in the RCM. However, the RegCM4 root mean square error is either similar to or larger than that in ECHAM5; this is due to the finer resolution of the former.

The temperature climatology is displayed in Fig. 4a-e for the CRU, the driving data (ERA40 and ECHAM5) and the RCM simulations (ERA40RegCM4 and ECHAM5-RegCM4). Their biases with respect to CRU and the differences between the 2 boundary forcings and between the 2 simulations are, respectively, presented in Fig. 5a-f. Table 1 summarizes the regional mean bias for temperature and the root mean square error over the NAP and SAP sub-domains. 

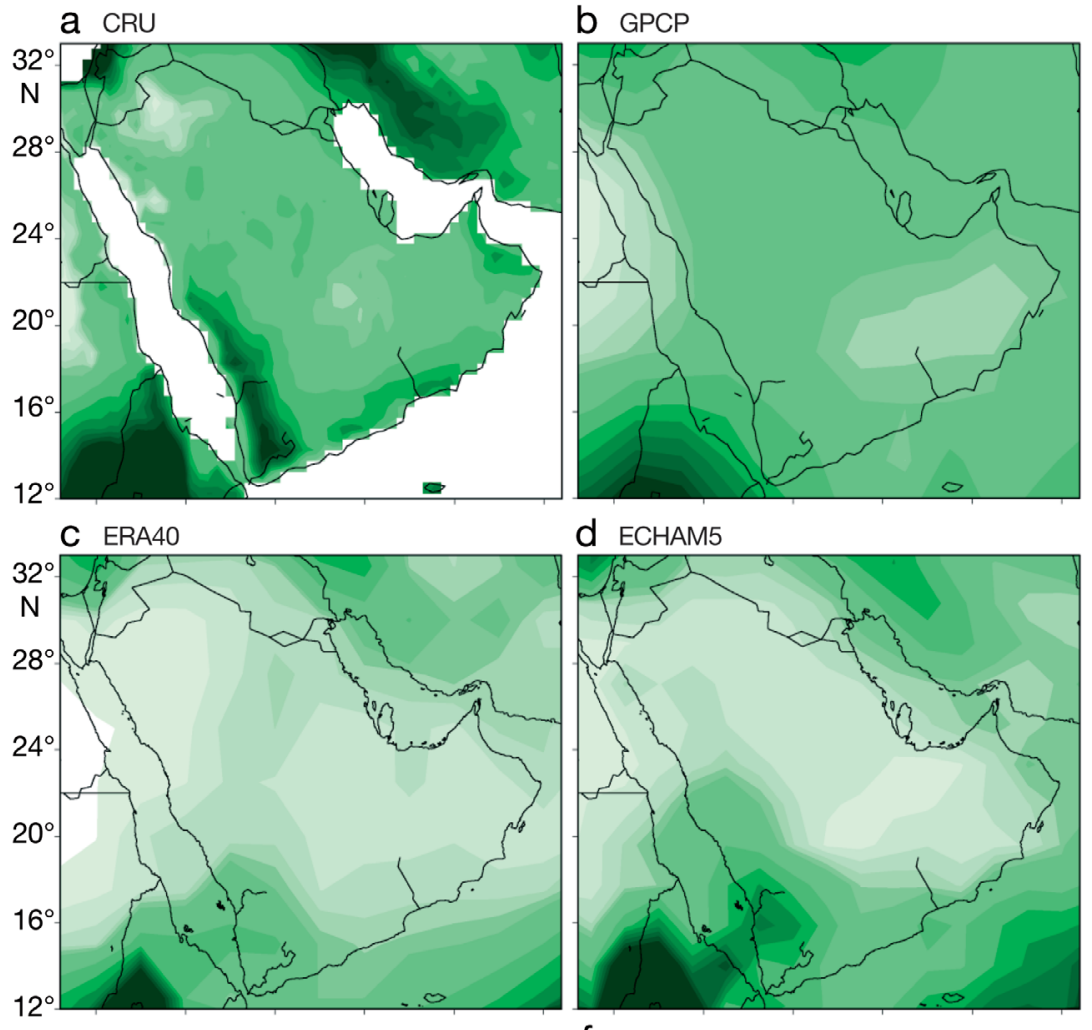

d ECHAM5
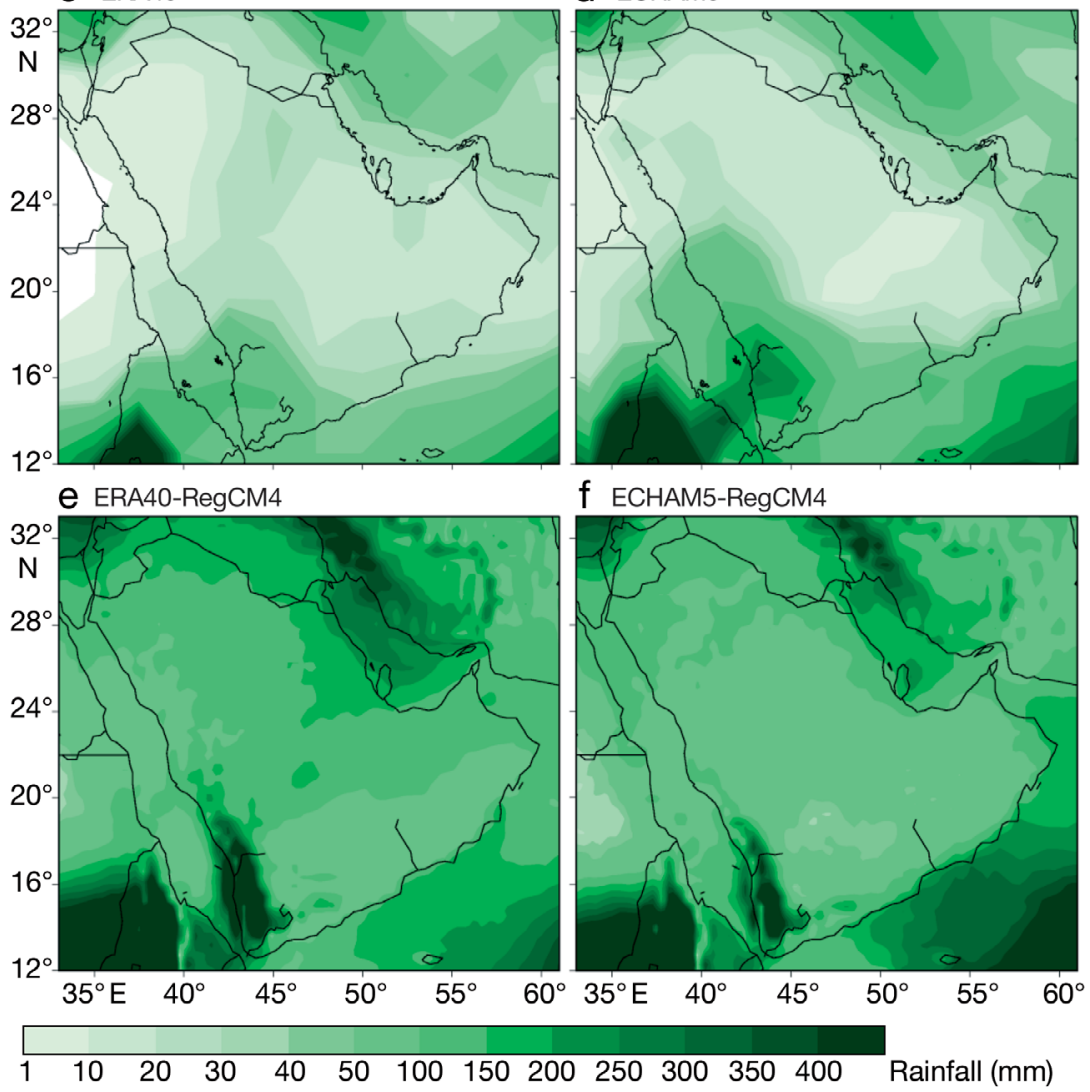

Fig. 2. Spatial distribution of annual mean rainfall for (a) CRU (Climate Research Unit), (b) GPCP, (c) ERA40, (d) ECHAM5, (e) ERA40-RegCM4, and (f) ECHAM5-RegCM4. Rainfall is averaged for the period 1979-2000, and units are millimeters per year. Model abbreviations, see Table 1 minima, but evidently reveal large overestimates (with differing magnitudes). ERA40 and ECHAM5 show similar distributions by locating the warmest bias (up to $7^{\circ} \mathrm{C}$ ) in the southwest, which decreases northeastwards, although the global model is cooler than the reanalysis by about $2{ }^{\circ} \mathrm{C}$. The 2 RegCM4 simulations decrease both the spatial extent and the magnitude of the warm bias shown in the driving fields and confine them to (mainly) over the southwesternmost land area of the peninsula, resulting in a regional bias of $<2^{\circ} \mathrm{C}$ in NAP and $4.5^{\circ} \mathrm{C}$ in SAP. This lower warm bias compared to the driving fields also results from the larger rainfall amounts, which would lead to more evaporative cooling in the RCM simulation. Note that over most of the land areas, the difference between the 2 RegCM4 simulations is $<0.5^{\circ} \mathrm{C}$.

It is thus evident that, for both temperature and precipitation, the RCM modifies the spatial bias pattern of the driving fields, reduces the gap between them, and improves the simulation of rainfall with respect to the forcing of the AOGCM in both magnitude and spatial distribution. These improvements have been reported by other authors over their regions of interest (e.g. Gao et al. 2006) and are probably due to the more realistic representations of local topography and surface conditions, which are better resolved at higher resolution (Giorgi \& Mearns 1999, Brankovic \& Gregory 2001, Rauscher et al. 2010).
The CRU data locate the warmest temperatures in the regions adjacent to the Arabian Gulf and at the center of the peninsula. The northern parts of the peninsula and the complex terrain in the southwest (facing the Arabian and Red Seas), where the amount of rainfall is higher, experience the lowest temperatures. ERA40 and ECHAM5, as well as ERA40-RegCM4 and ECHAM5-RegCM4, capture the spatial distributions of temperature maxima and

\subsection{Mean climatology of low-level wind and geopotential height}

Having examined the differences among the driving fields and the RegCM4 simulations, here we analyze low-level wind, specific humidity and geopotential height, in order to investigate the origins of the discrepancies and explain the reasons why the RCM appears to improve the driving global climate model. 
a ERA40 minus CRU

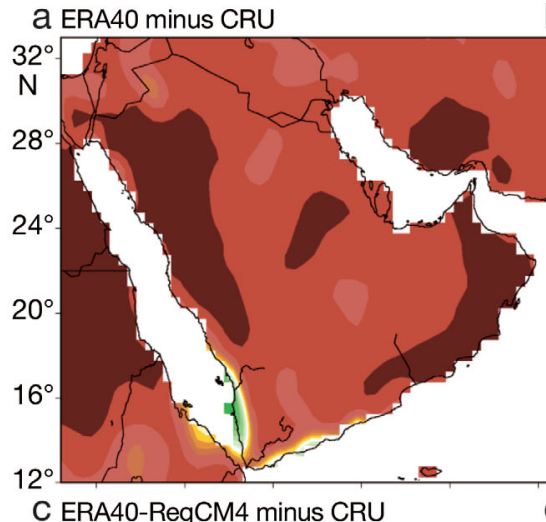

D ECHAM5 minus CRU
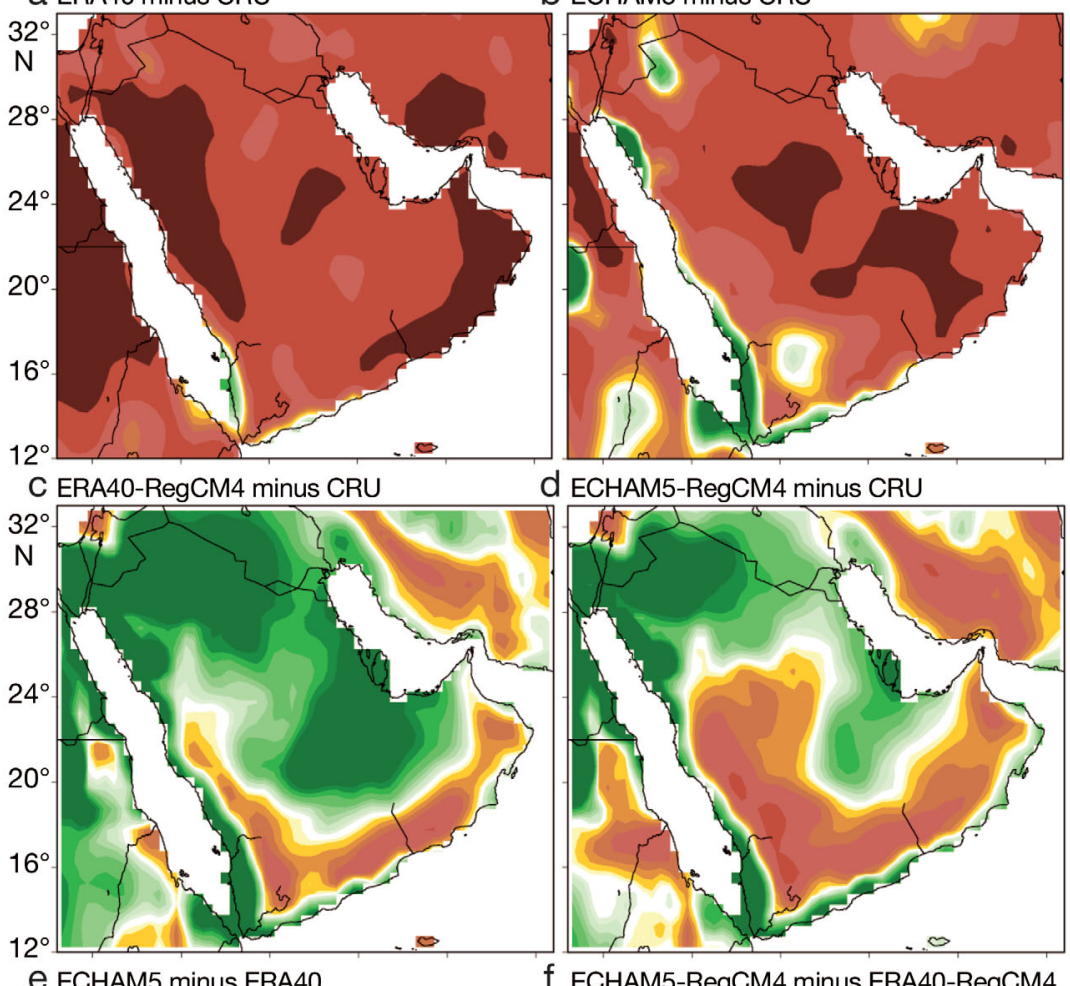

促

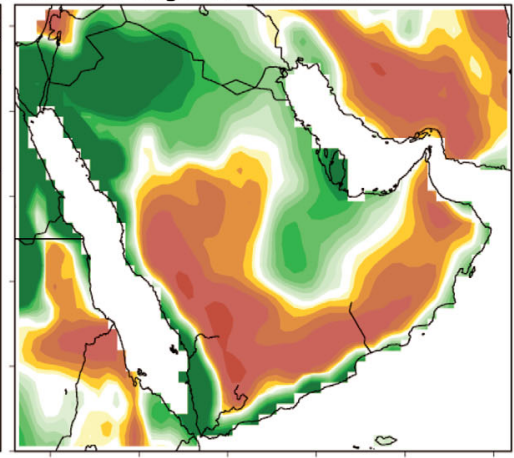

e ECHAM5 minus ERA40
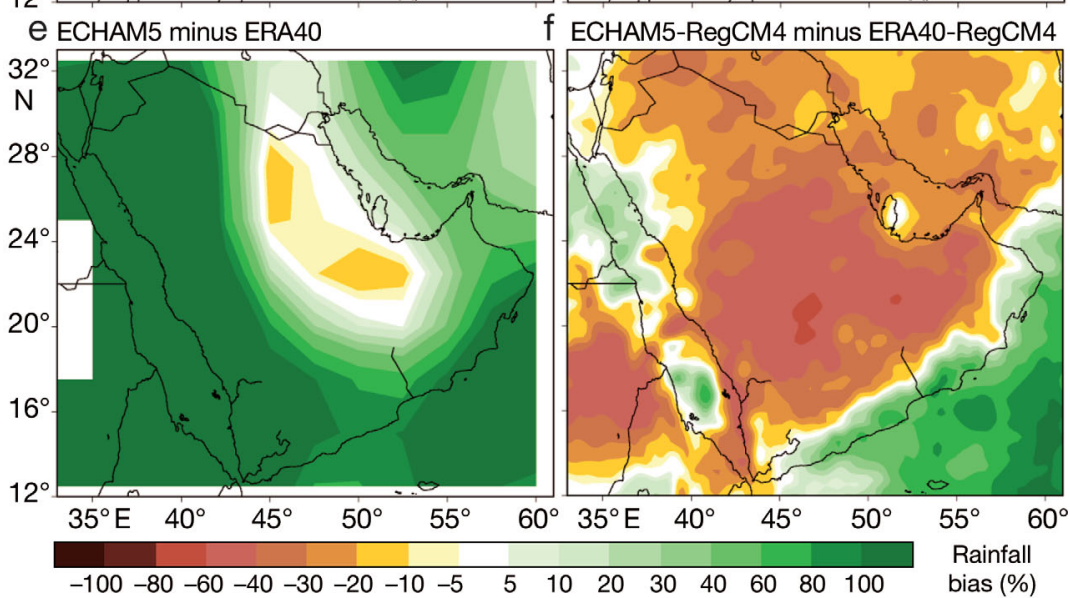

Fig. 3. Spatial distribution of rainfall bias for (a) ERA40 minus CRU, (b) ECHAM5 minus CRU, (c) ERA40-RegCM4 minus CRU, (d) ECHAM5-RegCM4 minus CRU, (e) ECHAM5 minus ERA40, and (f) ECHAM5-RegCM4 minus ERA40-RegCM4. Biases are averaged for the period 1979-2000 and are given in percentages of CRU values

The lower atmospheric level specific humidity and superimposed wind fields for ERA40, ECHAM5, ERA40-RegCM4, and ECHAM5-RegCM4, along with the differences between the driving fields and between the RegCM4 simulations, are shown in Fig. 6a-f. The reanalysis and global climate model exhibit southerly flows from the Arabian Sea towards land, which explains the larger specific humidity along the regions adjacent to the sea. Other regions of the Arabian Peninsula are predominantly dry, probably because of the northerly inflow, spinning west around the center, and hence transporting inland moisture away from the peninsula. It should be noted that the humidity values derived from ECHAM5 are significantly lower and the northerlies consistently stronger than in ERA40 over the entire peninsula. In both RegCM4 simulations, the specific humidity is higher over the Arabian Sea and lower in the adjacent land areas than in the reanalysis, as a consequence of an underestimation of the southerly winds from the Arabian Sea. Although the moisture amounts are lower in ECHAM5-RegCM4 than in ERA40-RegCM4, the difference between them is much less than the difference found when comparing ECHAM5 with ERA40, indicating the role of the RCM's internal dynamics and physics in determining local climates. The higher humidity amounts evident in ERA40-RegCM4 (compared to ECHAM5-RegCM4), due to stronger low-level southerly winds from the Arabian Sea, are consistent with its higher rainfall totals.

The corresponding lower level (925 hPa) of geopotential height fields and differences are shown in Fig. 7a-f; typically, lower heights represent lower pressure and higher heights represent higher pressure. For the Arabian Peninsula, both ERA40 and ECHAM5 show convergence in a few locations over the center, and over the southeastern and southwestern regions adjacent to the Arabian and Red Seas, respectively, but show divergence over the north. Although RegCM4 captures the locations of ridges and troughs, the heights are overestimated in both simulations. In addition, while the differences in the driving fields exhibit a dipole pattern over land, the ECHAM5-RegCM4 heights are generally greater than those in ERA40-RegCM4 over the north. This is consistent with the stronger northerlies, the lower specific humidity, and the lower, but more realistic, rainfall amounts found in the RegCM4 driven by ECHAM5. 


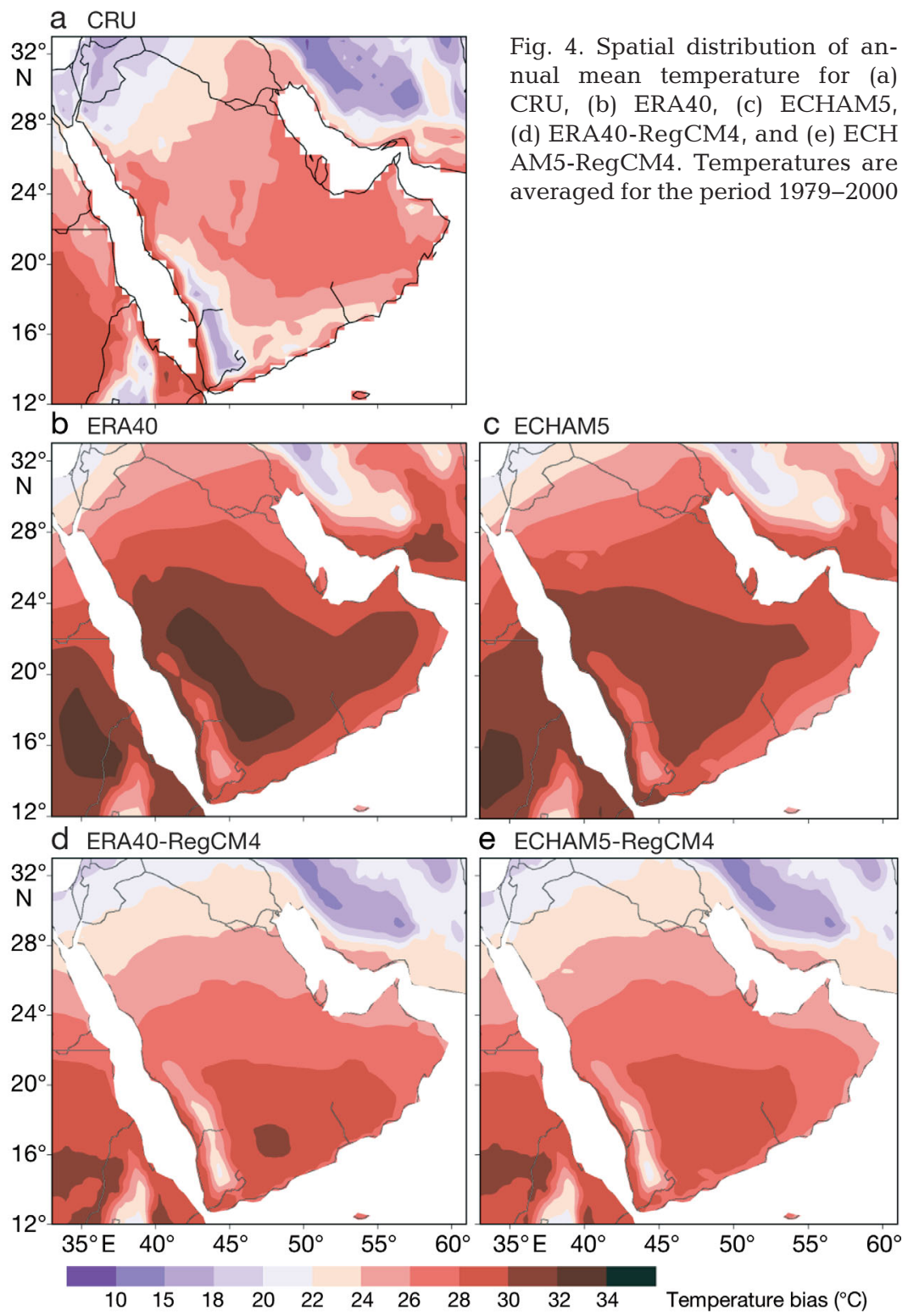

fairly good monthly variability when compared with CRU observations, by capturing the wet and dry seasons, as well as occurrences of peaks and minima of monthly rainfall amounts, resulting in high correlation coefficients (0.92 and 0.84). Note that the ERA40RegCM4 tends to substantially overestimate the peak in March-April, and that the ECHAM5-RegCM4 shows more reasonable values with respect to the CRU data.

In the SAP sub-region, the CRU observations exhibit strong variability throughout the year (Fig. 8b), mostly peaking in April, July, and December. GPCP also shows some monthly variability in this region, but in a unimodal annual cycle, peaking in May. The ERA40's rainfall is similar to the GPCP's, but with much weaker maxima. ECHAM5 and ECHAM5RegCM4 fail to reproduce any of the observed annual cycles, whereas ERA 40-RegCM4 succeeds, but largely overestimates the maxima in MarchApril and July-August.

Overall, when comparing the ECH AM5 and ECHAM5-RegCM4 in simulating the mean annual cycles of rainfall, it is apparent that the RCM captures the variability in terms of amplitude and phase much better, with a higher correlation coefficient (0.84 versus 0.63 ), thereby improving the driving global model in the NAP sub-region, while over the SAP subregion, it follows the driving AOGCM forcings $(0.13$ and 0.16 for correlation

\subsection{Mean annual cycle}

The mean annual cycle, calculated by area-averaging the rainfall over the NAP and SAP sub-regions (see Fig. 1a) for CRU, GPCP, the 2 driving fields, and the 2 simulations is displayed in Fig. 8, while Table 1 provides their correlation coefficients. Over NAP, the CRU observational data exhibit a double-peaked annual cycle with maxima occurring in March and November, and a summer drought from June to September. This behavior of the annual cycle is not found in the GPCP data. The 2 driving datasets (ERA40 and ECHAM5) show minimal rainfall amounts throughout the whole year. Both RegCM4 simulations display coefficients, respectively). These indicate that, in the NAP, the annual rainfall cycle is driven mostly by the internal dynamics and physics of the RCM, while, in the SAP, the influence is dominated by large-scale conditions provided by the driving AOGCM lateral boundary forcings. This is probably because of the proximity of the SAP sub-region to both the Red and Arabian Seas, and the subsequent effects of SSTs.

Unlike precipitation, the monthly temperature variability (Fig. 9a-b) shows a unimodal peak in the annual cycle over the NAP and SAP sub-regions, with the warmest period being June-August. The 2 driving fields capture the phase of the annual cycle 


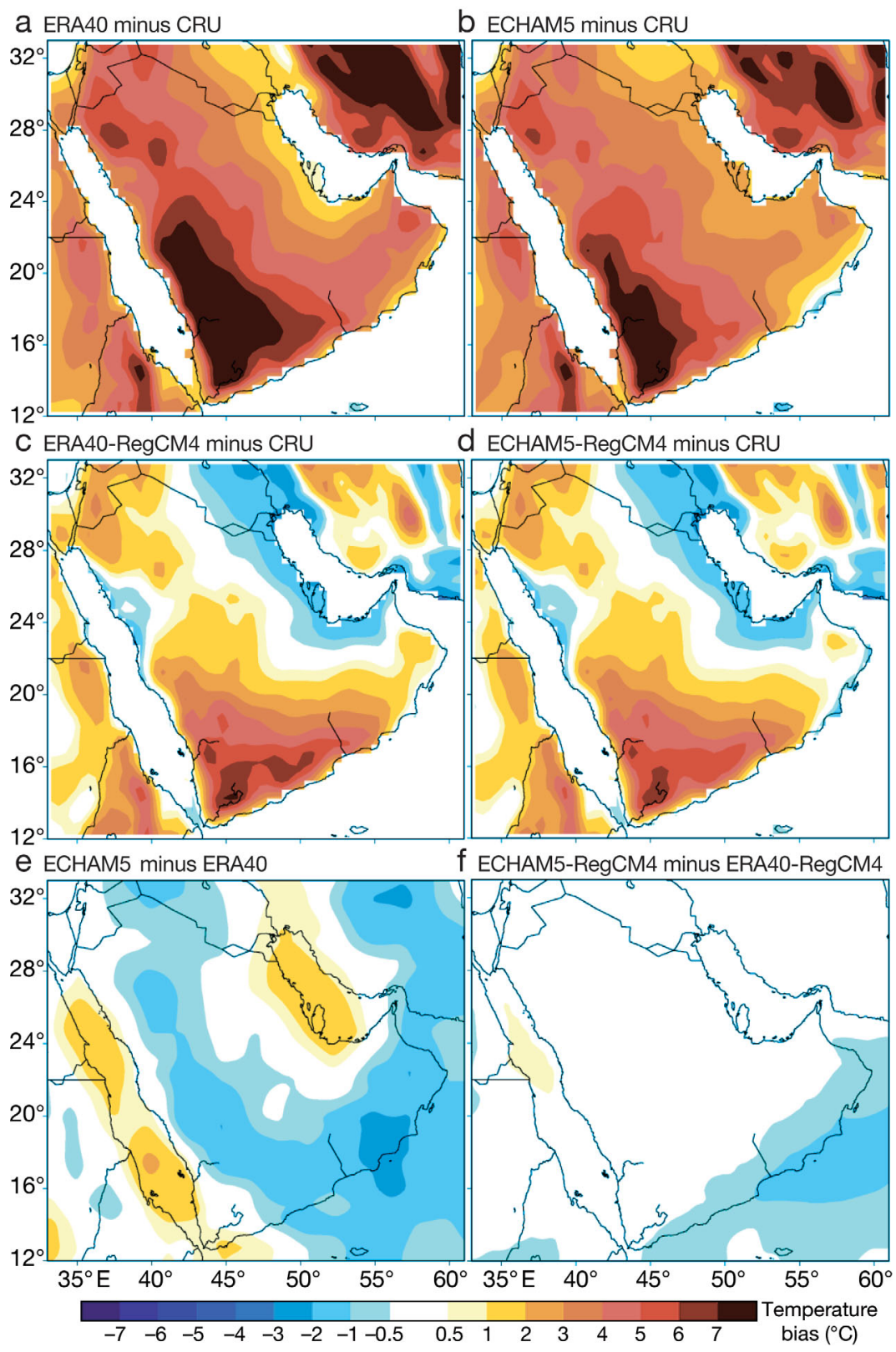

Fig. 5. Spatial distribution of temperature bias for (a) ERA40 minus CRU, (b) ECHAM5 minus CRU, (c) ERA40-RegCM4 minus CRU, (d) ECHAM5-RegCM4 minus CRU, (e) ECHAM5 minus ERA40, and (f) ECHAM5-RegCM4 minus ERA40-RegCM4. Biases are averaged for the period 1979-2000

driving global model by damping the amplitude of the seasonal cycle and, therefore, providing temperature values closer to those from the CRU observations.

Improvements in the simulation of annual cycles by RCMs have also been investigated over other regions, but the results are regionally dependent. In fact, Seth et al. (2007) found their RCM slightly outperforming the driving global model in reproducing the seasonal cycle only over northern Brazil. In contrast, Im et al. (2007) showed that the regional model agrees better with observations than the global model, both in terms of seasonal evolution and precipitation amounts over East Asia. Sylla et al. (2009) found that for the annual precipitation and temperature cycles of the West African climate, both regional and global models perform well in simulating phases and amplitudes and that the regional model increases the temporal correlation mainly over arid and semi-arid regions. Thus, RCMs do not systematically improve the representation of seasonal cycles for rainfall and temperature. However, the Arabian Peninsula appears to be very sensitive to dynamical downscaling, which nevertheless improves the monthly variability of the driving fields in both phase and amplitude.

\subsection{Interannual variability}

Having examined and compared the mean spatial patterns and annual cycles of rainfall and temperature from and between the dri-

very well (correlation coefficients $>0.90$ ), but are generally warmer throughout the whole year, hence explaining the large positive temperature bias found in climatology results. The ECHAM5-RegCM4 and ERA40-RegCM4 also reproduce the annual cycle (with correlation coefficients $>0.90$ ); however, overall, the simulated monthly temperatures are higher than those observed, but lower than those in the driving fields. It is thus clear that the RCM corrects the ving data and the nested RCM, here we evaluate the overall interannual variability by performing variance analyses of yearly average rainfall and

Fig. 6. Spatial distribution of lower atmospheric level annual average wind fields $\left(\mathrm{m} \mathrm{s}^{-1}\right)$ superimposed on specific humidity for (a) ERA40, (b) ECHAM5, (c) ERA40-RegCM4, (d) ECHAM5-RegCM4, (e) ECAM5 minus ERA40, and (f) ECHAM5-RegCM4 minus ERA40-RegCM4 
a ERA40

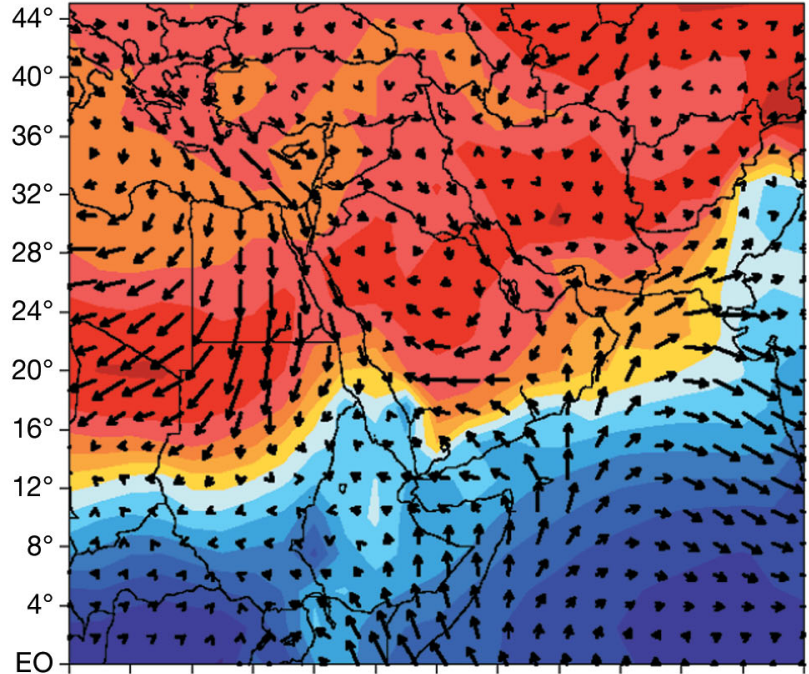

C ERA40-RegCM4

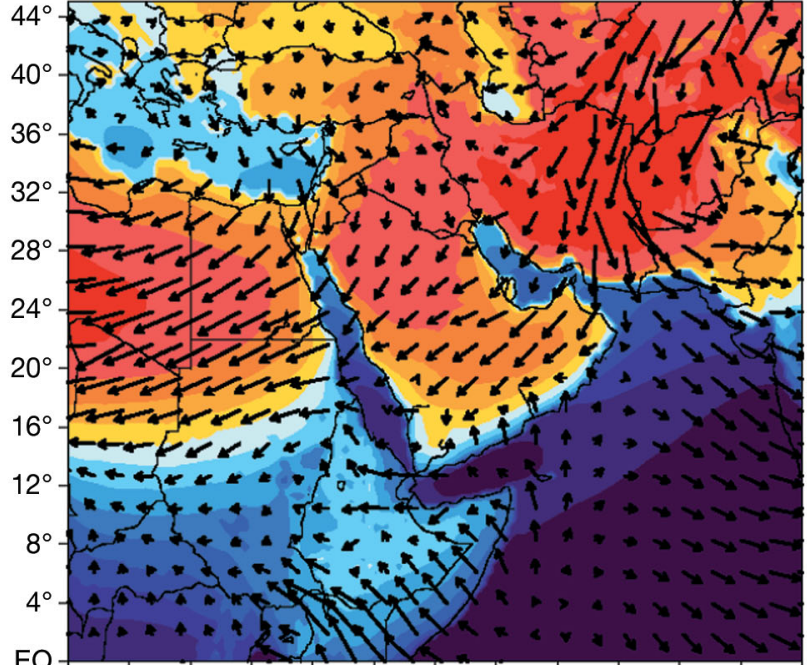

b ECHAM5

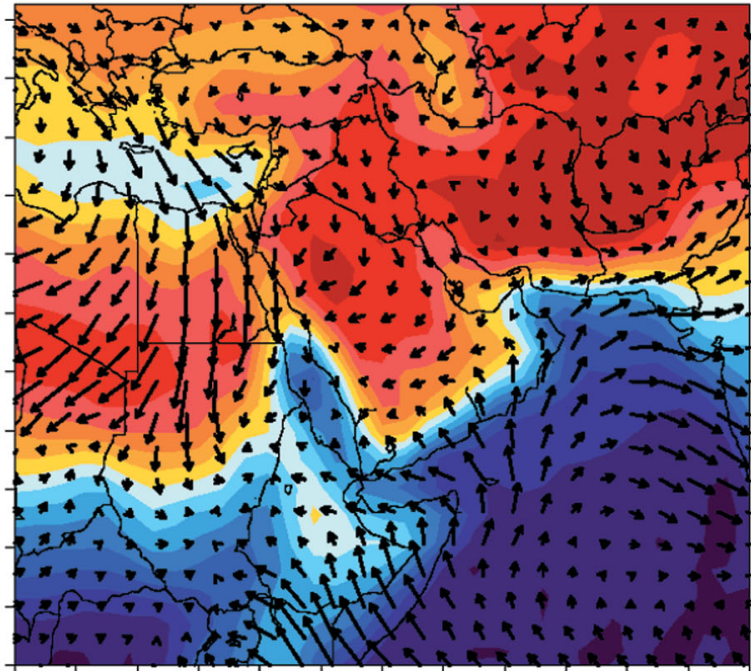

d ECHAM5-RegCM4

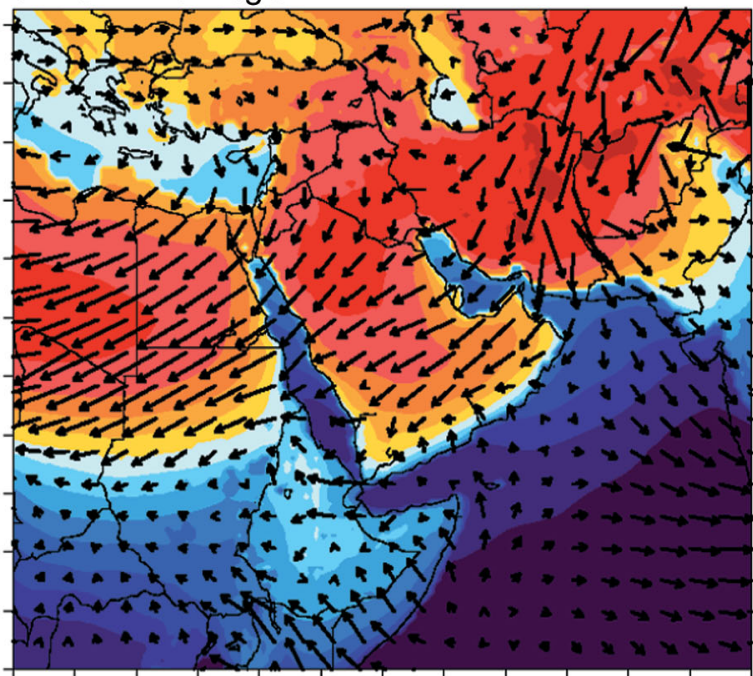

e ECHAM5 minus ERA40

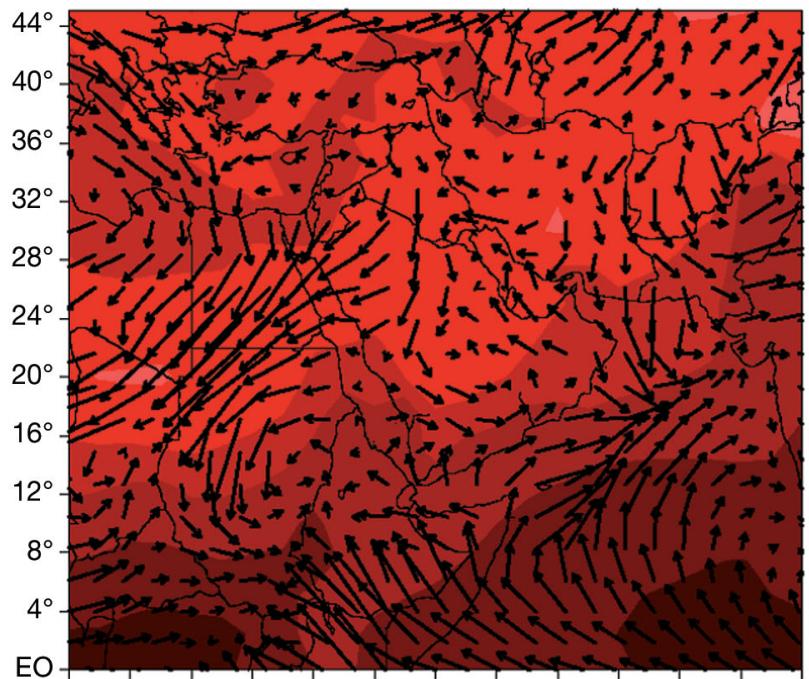

${ }^{2}$ ECHAM5-RegCM4 minus ERA40-RegCM4

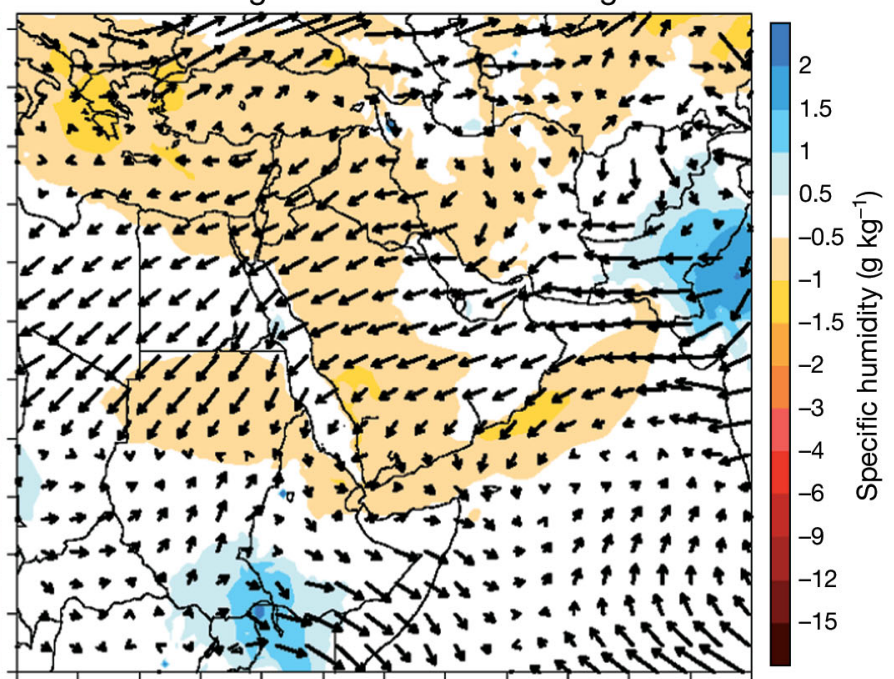

$15^{\circ} \mathrm{E} 20^{\circ} 25^{\circ} 30^{\circ} 35^{\circ} \quad 40^{\circ} \quad 45^{\circ} 50^{\circ} \quad 55^{\circ} \quad 60^{\circ} \quad 65^{\circ} \quad 70^{\circ} \quad 15^{\circ} \mathrm{E} 20^{\circ} \quad 25^{\circ} 30^{\circ} 35^{\circ} \quad 40^{\circ} \quad 45^{\circ} 50^{\circ} 55^{\circ} \quad 60^{\circ} \quad 65^{\circ} \quad 70^{\circ}$ 
a ERA40
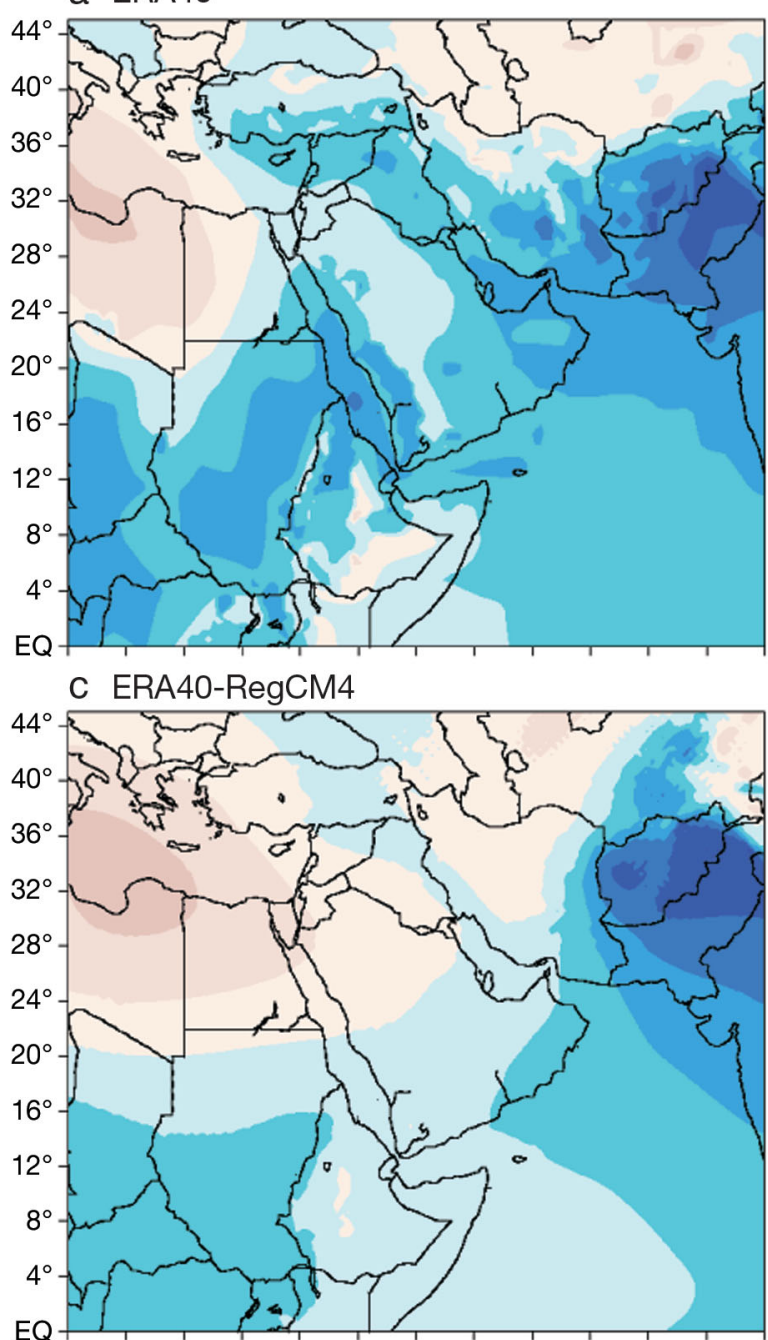

\section{e ECHAM5 minus ERA40}

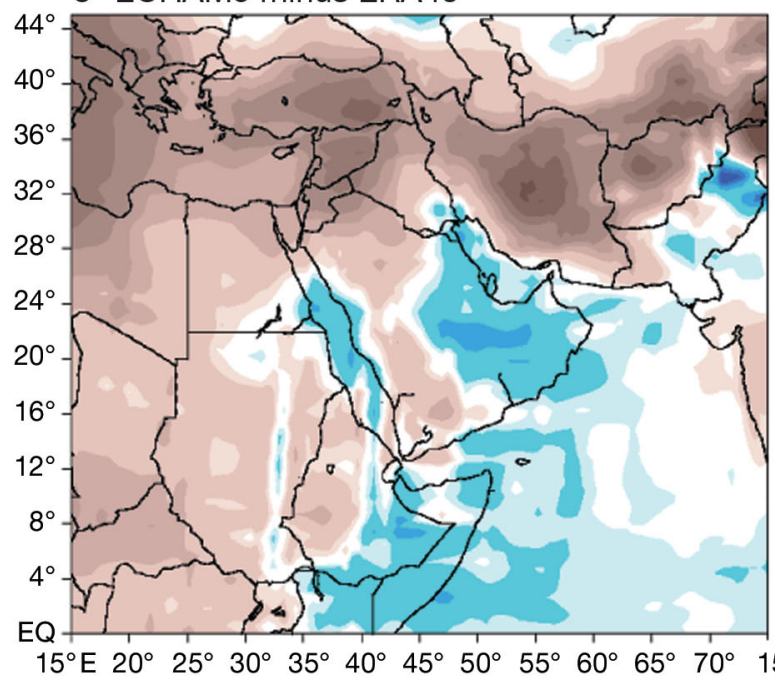

\section{b ECHAM5}

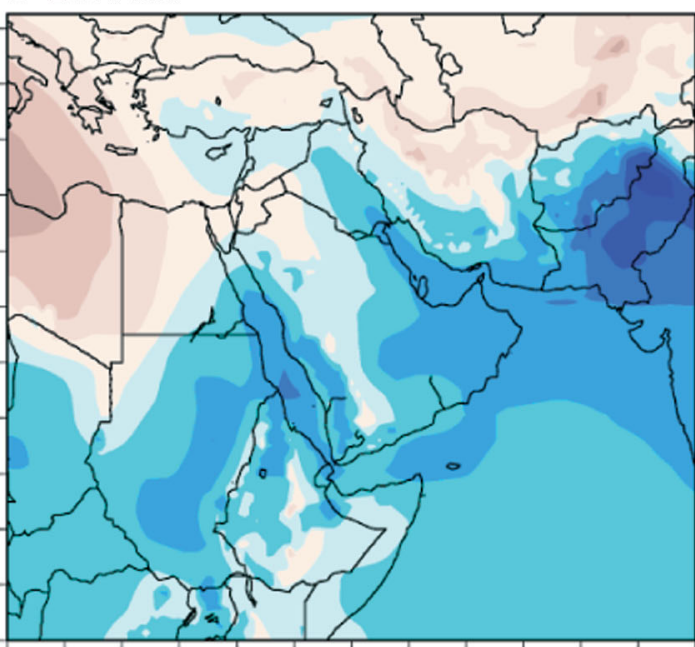

\section{d ECHAM5-RegCM4}

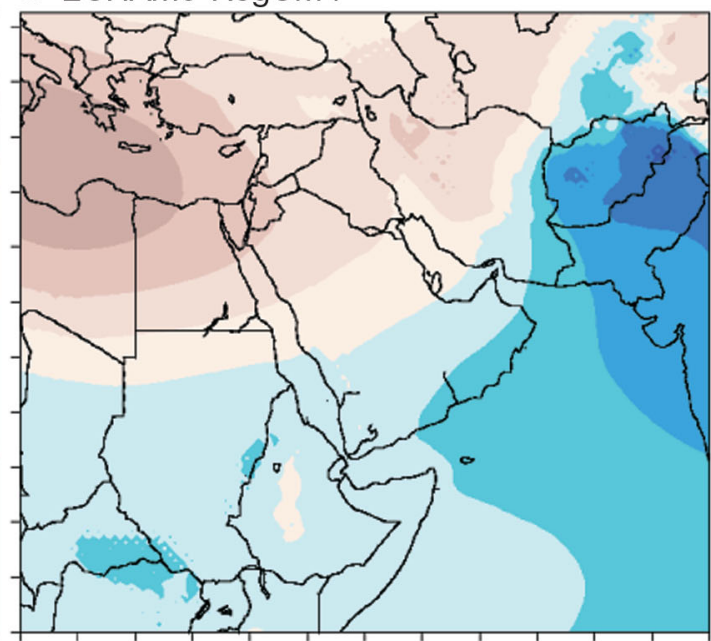

\section{$f$ ECHAM5-RegCM4 minus ERA40-RegCM4}

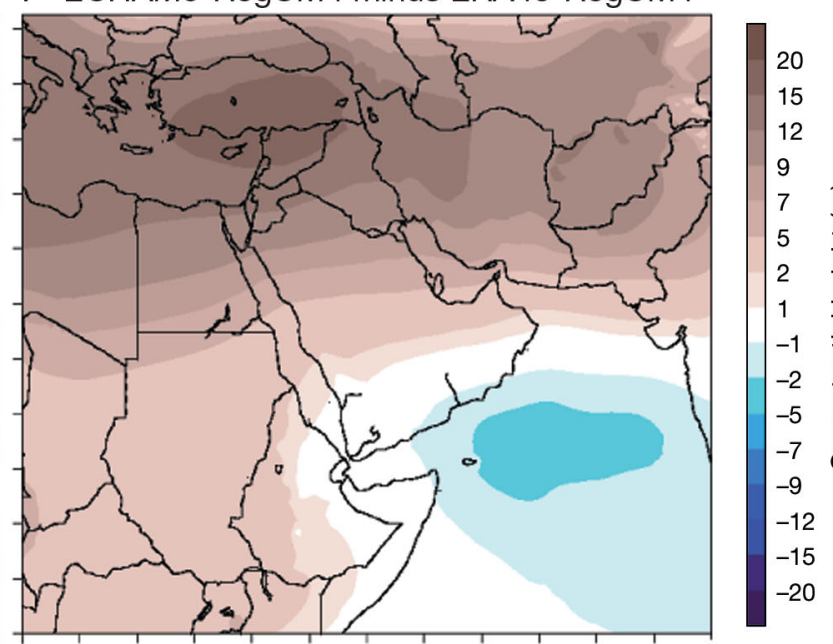

870

860

850

840

830

820 810 है 800 충 $780 \frac{\bar{\sigma}}{\sigma}$ 770 : 760 市 750 응 740 ऽ

730

720

Fig. 7. Spatial distribution of lower atmospheric level (925 hPa) annual average geopotential height (m) for (a) ERA40, (b) ECHAM5，(c) ERA40-RegCM4，(d) ECHAM5-RegCM4，(e) ECAM5 minus ERA40, and (f) ECHAM5-RegCM4 minus ERA40-RegCM4 


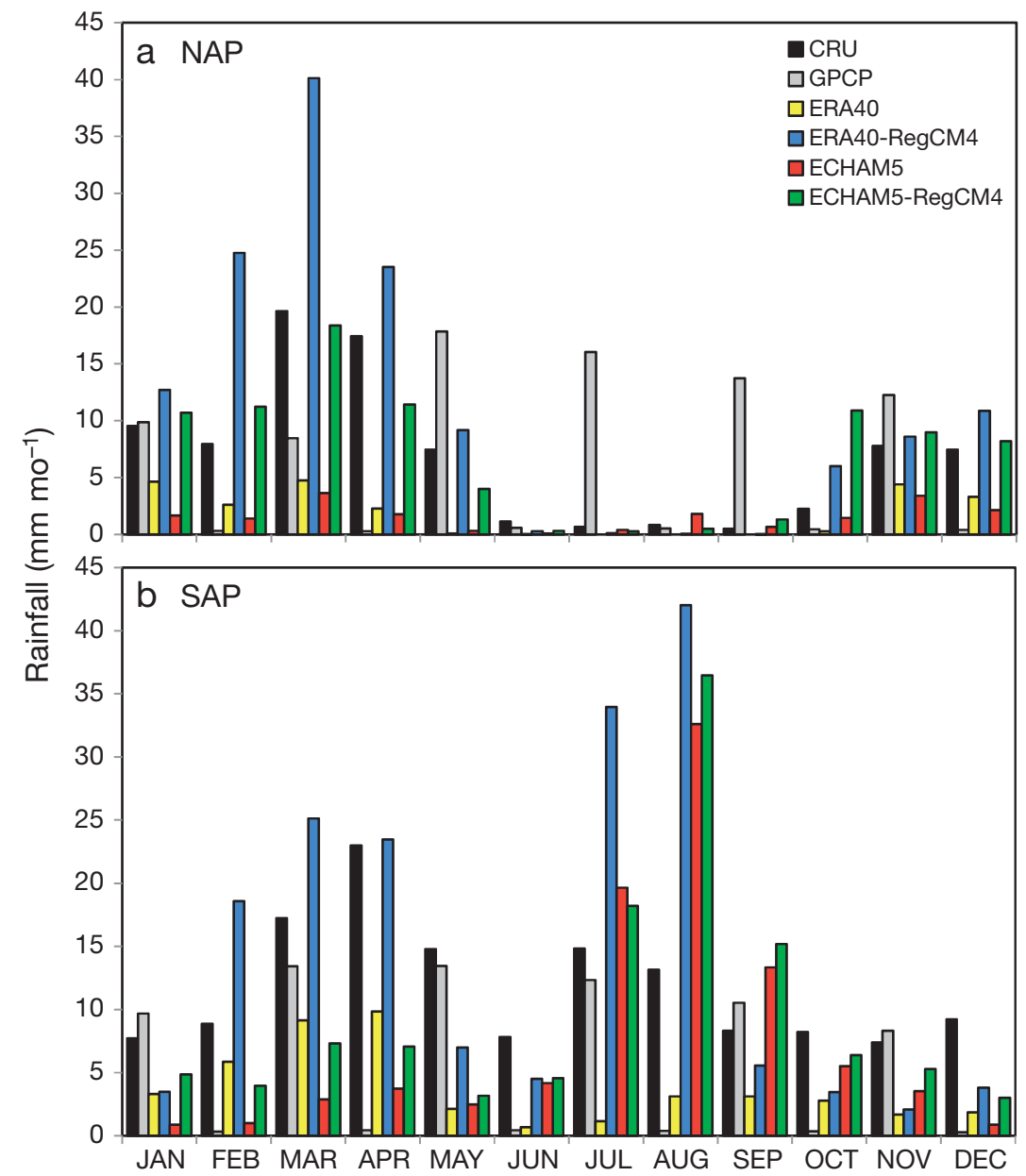

Fig. 8. Annual cycle of area-averaged rainfall over the 2 sub-regions, (a) northern Arabian Peninsula (NAP) and (b) southern Arabian Peninsula (SAP), for CRU, GPCP, ERA40, ERA40-RegCM4, ECHAM5, and ECHAM5-RegCM4. Monthly data are averaged over 1979-2000 between CRU and GPCP is largely reduced, and the RegCM4 simulations, along with the forcing fields, provide values of the coefficient of variance similar to or a little higher (in ECHAM5-RegCM4) than those of GPCP. The year-to-year temperature variability is significantly lower than that of rainfall. In the NAP sub-region, ECHAM5 considerably underestimates the temperature variability with respect to $\mathrm{CRU}$; ERA40-RegCM4 slightly overestimates it, while ECHAM5-RegCM4 provides temperature variance closer to the CRU data. Concerning the SAP sub-region, the temperatures from the driving fields and the simulations do not show any significant differences compared to CRU data. Note that the coefficients of variance for both temperature and rainfall are lower in SAP than in NAP. Generally, the models and reanalysis perform better in SAP, where the variance is lower than in NAP (where the variability is larger). Comparing the different models, for the variance analysis, it is clear that the regional model does not systematically outperform the driving ECHAM5; it does, however, show mixed benefits. temperature for the period 1979-2000 for the NAP and SAP sub-regions.

The overall variability measured by the coefficient of variance is displayed in Fig. 10a,b for precipitation and temperature, respectively. For rainfall, we use the 2 observational datasets (CRU and GPCP) to account for uncertainties. Over the NAP sub-region, the coefficient of variance in GPCP is substantially larger than that of the CRU, indicating more year-toyear rainfall variability. All the experiments, along with their driving fields, tend to simulate variability within the range of the observations; however, ECHAM5-RegCM4 provides the larger coefficient. The discrepancy in observations, however, makes it difficult to unambiguously assess the performance of each experiment and to examine whether the RCM outperforms the AOGCM in simulating the overall variability. In the SAP sub-region, the difference

\section{CONCLUSIONS}

In the present paper, we evaluated and compared multi-decadal present-day climate simulations of a coarse-resolution driving global climate model (ECHAM5) and a nested RCM (RegCM4) to correctly represent mean climatology of rainfall and temperature, along with their annual cycles and interannual variability, over the Arabian Peninsula. The RegCM4 is also driven by ERA40 boundary forcing, and the results have been discussed and compared.

The RCM, the reanalysis, and the global climate model capture the main features of the spatial distribution of rainfall well. However, the driving fields are somewhat drier over the entire peninsula and miss the higher intensity of rainfall over the coastal areas of regions adjacent to the Red Sea, where the topography is characterized by steep gradients. In 


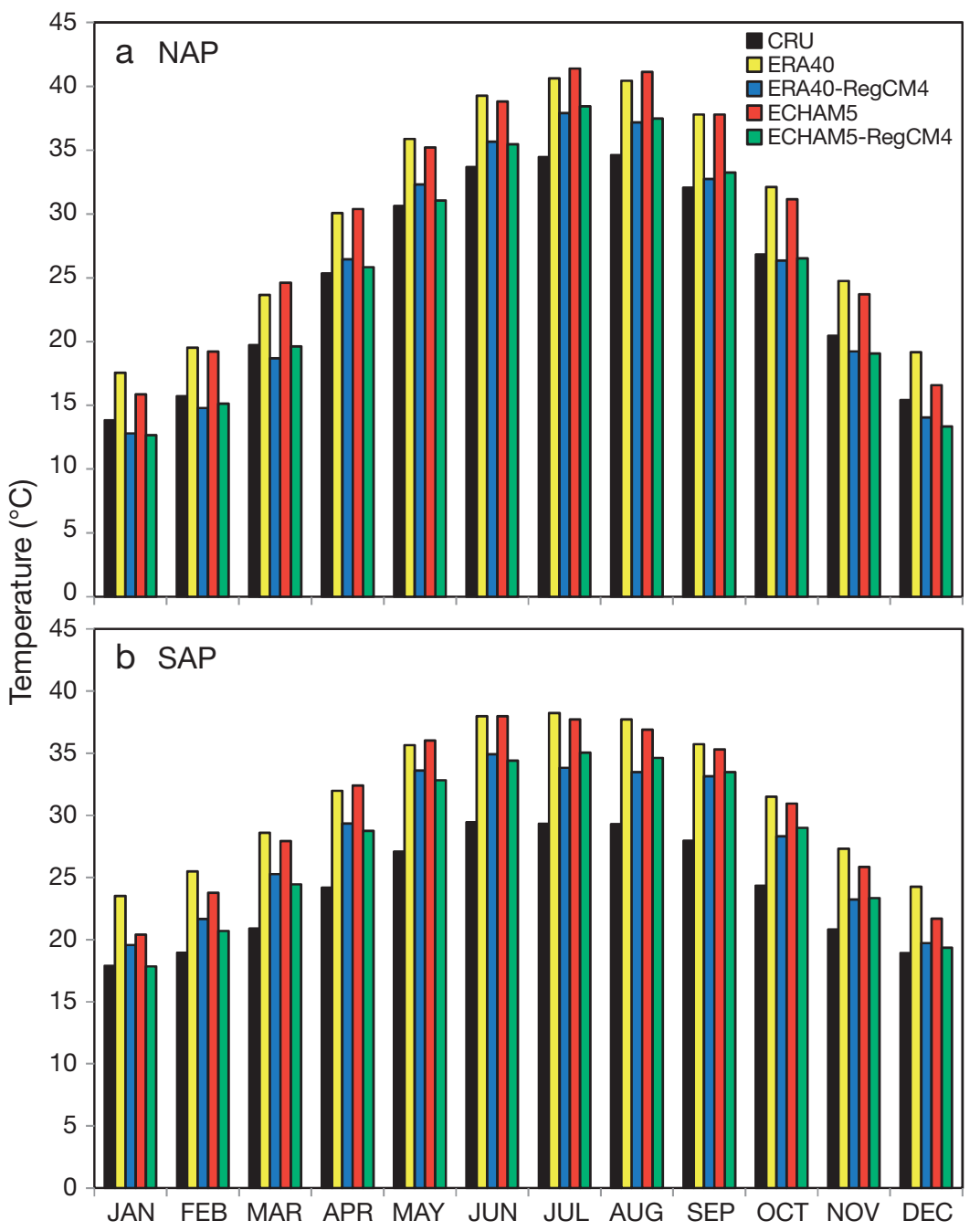

Fig. 9. Annual cycle of area-averaged temperature over the 2 sub-regions, (a) Arabian Peninsula (NAP) and (b) southern Arabian Peninsula (SAP), for CRU, ERA40, ERA40-RegCM4, ECHAM5, and ECHAM5-RegCM4. Monthly data are averaged over 1979-2000

contrast, the RegCM4 simulations show higher rainfall intensity over a larger area of the peninsula, consistent with CRU and GPCP observations. In addition, the RegCM4 captures the maxima along the Red Sea coast well, probably because of better representation of the coastal mountains. As a result, although their temperature spatial distributions are both close to the CRU data, the drier ERA40 and ECHAM5 display warmer surface temperatures than the RegCM4, suggesting the occurrence of greater evaporative cooling and cloud cover, which tend to decrease and offset the incoming solar energy and therefore the warming. Thus, the RegCM4 appears to outperform the global model, for the most part, in simulating the spatial distributions of rainfall and temperature. This improvement originates almost certainly from the more realistic simulation of specific humidity, overlapping wind fields, and geopotential heights.

In addition, the annual cycles of rainfall and temperature from both models have been analyzed and compared in 2 Arabian Peninsula sub-regions: a northern (NAP) and a southern (SAP) sub-region. The RCM offers some improvements regarding the magnitude of the temperature variability in both regions, while, for precipitation, it has mixed benefits. In fact, it performs better only over the NAP sub-region, while, in the SAP, it mostly follows the driving AOGCM forcings.

Finally, the interannual variability, represented by the coefficient of variance of yearly averaged values of rainfall and temperature, suggests that the variability is much higher in NAP than in SAP. Overall, both RegCM4 and ECHAM5 perform similarly in terms of variance over the low-variability region (SAP); however, the RCM improves the AOGCM in connection with the high variability occurring over the NAP region. This suggests that, for both temperature and precipitation, the variability (annual cycle and variance) over NAP seems to be more linked to regional processes (represented by internal RCM dynamics and physics), while, over the SAP sub-region, they appear to be driven more strongly by large-scale forcings.

In general, our dynamical downscaling results enable clearer interpretation of projections over the Arabian Peninsula, and we plan to use this tool to generate information on regional climate change in the region within the framework of the CORDEX (Coordinated Downscaling Experiments) (Giorgi et al. 2009).

Acknowledgements. The author acknowledges the RegCM4 group of the Abdus Salam International Centre for Theoretical Physics (ICTP), Trieste, Italy, for providing the model with boundary forcings. CRU (www.cru.uea.ac.uk) and GPCP (www.cgd.ucar.edu/) are also acknowledged for providing the gridded datasets. 

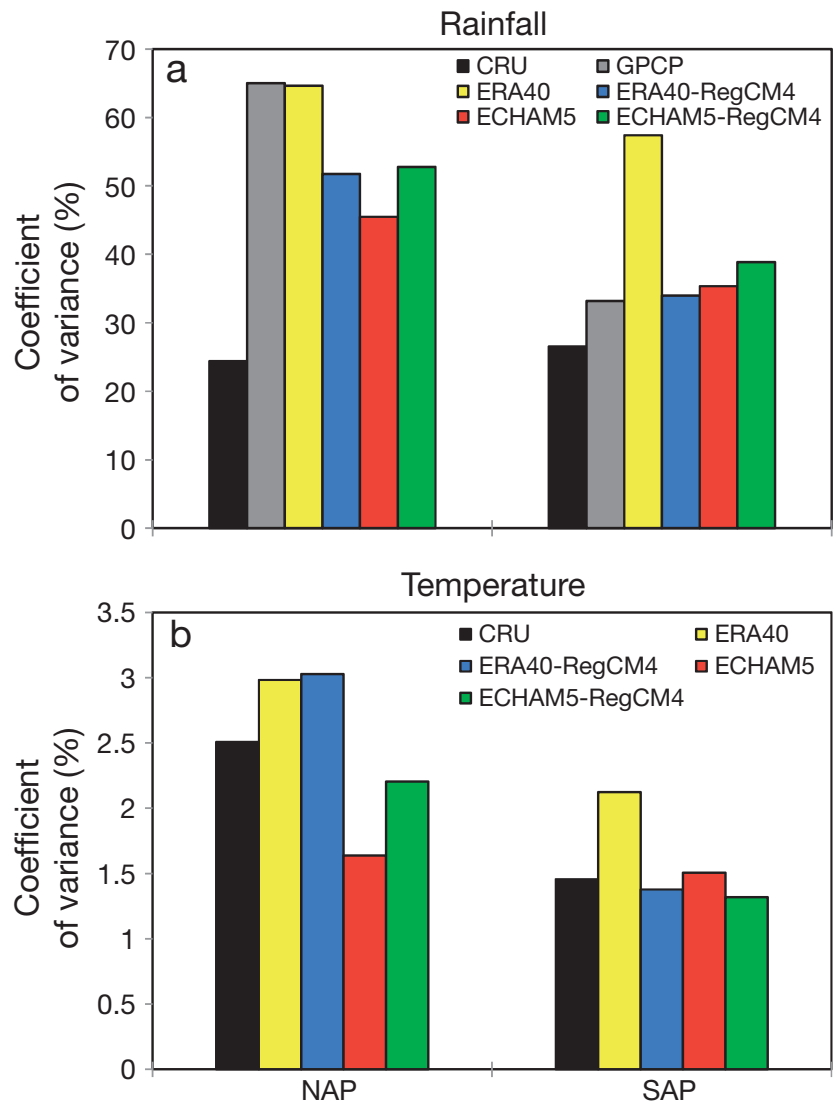

Fig. 10. Coefficients of variance for (a) rainfall and (b) temperature in the 2 sub-regions, the northern Arabian Peninsula (NAP) and southern Arabian Peninsula (SAP), for CRU, ERA40, ERA40-RegCM4, ECHAM5, and ECHAM5-RegCM4. For rainfall the available variances for GPCP are also included

\section{LITERATURE CITED}

Abdullah MA, Al-Mazroui MA (1998) Climatological study of the southwestern region of Saudi Arabia. I. Rainfall analysis. Clim Res 9:213-223

Adler RF, Huffman GJ, Chang A, Ferraro R and others (2003) The Version-2 Global Precipitation Climatology Project (GPCP) monthly precipitation analysis (1979present). J Hydrometeorol 4:1147-1167

Almazroui M (2011a) Sensitivity of a regional climate model (RegCM3) on the simulation of high intensity rainfall events over the Arabian Peninsula and around Jeddah (Saudi Arabia). Theor Appl Climatol 104:261-276

Almazroui M (2011b) Calibration of TRMM rainfall climatology over Saudi Arabia during 1998-2009. Atmos Res 99:400-414

Anthes RA (1977) A cumulus parameterization scheme utilizing a one-dimensional cloud model. Mon Weather Rev 105:270-286

Brankovic C, Gregory D (2001) Impact of horizontal resolution on seasonal integrations. Clim Dyn 18:123-143

Chakraborty A, Behera SK, Mujumdar M, Ohba R, Yamagata T (2006) Diagnosis of tropospheric moisture over Saudi Arabia and influences of IOD and ENSO. Mon Weather Rev 134:598-617
Chenoweth J, Hadjinicolaou P, Bruggeman A, Lelieveld J and others (2011) Impact of climate change on the water resources of the eastern Mediterranean and Middle East region: modeled 21st century changes and implications. Water Resour Res 47:W06506. doi: 10.1029/2010WR010269

Christensen JH, Hewitson B, Busuioc A, Chen A and others (2007) Regional climate projections. In: Climate change 2007: the physical science basis. Contribution of Working Group I to the Fourth Assessment Report of the Intergovernmental Panel on Climate Change. Cambridge University Press, Cambridge, p 847-940

Dickinson RE, Henderson-Sellers A, Kennedy PJ (1993) Biosphere-atmosphere transfer scheme (BATS) version $1 \mathrm{e}$ as coupled to the NCAR community climate model. NCAR/TN-387 +STR, 72, NCAR, Boulder, CO

Diffenbaugh NS, Pal J, Trapp R, Giorgi F (2005) Fine-scale processes regulate the response of extreme events to global climate change. Proc Natl Acad Sci USA 102: 15774-15778

Emanuel KA (1991) A scheme for representing cumulus convection in large-scale models. J Atmos Sci 48:2313-2335

> Evans JP, Smith RB, Oglesby RJ (2004) Middle East climate simulation and dominant precipitation processes. Int $\mathrm{J}$ Climatol 24:1671-1694

Fritsch JM, Chappell CF (1980) Numerical prediction of convectively driven mesoscale pressure systems. I. convective parameterization. J Atmos Sci 37:1722-1733

$>$ Gao X, Pal JS, Giorgi F (2006) Projected changes in mean and extreme precipitation over the Mediterranean region from a high resolution double nested RCM simulation. Geophys Res Lett 33:L03706. doi:10.1029/2005 GL024954

Gao XJ, Zhang DF, Chen ZX, Pal JS, Giorgi F (2007) Simulation of land use effects on climate in China by RegCM3. Sci China D Earth Sci 50:620-628

- Giorgi F, Mearns LO (1999) Introduction to special section: regional climate modeling revisited. J Geophys Res 104(D6):6335-6352. doi:10.1029/98JD02072

Giorgi F, Bi X, Pal JS (2004) Mean, interannual variability and trends in a regional climate change experiment over Europe. Part I: present day climate (1961-1990). Clim Dyn 22:733-756

Giorgi F, Jones C, Asrar G (2009) Addressing climate information needs at the regional level: the CORDEX framework. WMO Bull 58:174-183

Giorgi F, Coppola E, Solmon F, Mariotti L and others (2012) RegCM4: model description and preliminary tests over multiple CORDEX domains. Clim Res 52:7-29

Grell GA, Dudhia J, Stauffer DR (1994) Description of the fifth-generation Penn State/NCAR Mesoscale Model (MM5). NCAR TN-398+STR, NCAR, Boulder, CO

Güttler I (2011) Reducing warm bias over the north-eastern Europe in a regional climate model. Croat Meteorol J 44/45:19-29

Holtslag AAM, de Bruijn EIF, Pan HL (1990) A high resolution air mass transformation model for short-range weather forecasting. Mon Weather Rev 118:1561-1575

Im ES, Kwon WT, Ahn JB, Giorgi F (2007) Multi-decadal scenario simulation over Korea using a one-way double nested regional climate model system. 1. Recent climate simulation (1971-2000). Clim Dyn 28:759-780

Islam MN (2009) Rainfall and temperature scenario for Bangladesh. Open Atmos Sci J 3:93-103

Jungclaus JH, Keenlyside N, Botzet M, Haak H and others (2006) Ocean circulation and tropical variability in 
the coupled model ECHAM5/MPI-OM. J Clim 19: 3952-3972

Kiehl JT, Hack JJ, Bonan GB, Boville BA, Breigleb BP, Williamson DL, Rasch PJ (1996) Description of the NCAR community climate model (CCM3). NCAR/TN-4201STR, 152, NCAR, Boulder, CO

Krichak S, Breitgand J, Samuels R, Alpert P (2011) A doubleresolution transient RCM climate change simulation experiment for near-coastal eastern zone of the eastern Mediterranean region. Theor Appl Climatol 103:167-195

Loveland TR, Reed BC, Brown JF, Ohlen DO, Zhu Z, Yang L, Merchant JW (2000) Development of a global land cover characteristics database and IGBP DISCOVER from 1-km AVHRR data. Int J Remote Sens 21:1303-1330

Marcella MP, Eltahir EAB (in press) Modeling the summertime climate of Southwest Asia: the role of land surface processes in shaping the climate of semi-arid regions. J Clim 25:704-719

Meehl GA, Covey C, Delworth T, Latif M and others (2007) The WCRP CMIP3 multimodel dataset: a new era in climate change research. Bull Am Meteorol Soc 88: 1383-1394

Mitchell TD, Carter TR, Jones PD, Hulme M, New M (2004) A comprehensive set of high-resolution grids of monthly climate for Europe and the globe: the observed record (1901-2000) and 16 scenarios (2001-2100). Tyndall Centre Working Paper No. 55, Tyndall Centre for Climate Change Research, University of East Anglia, Norwich

Pal JS, Eltahir EAB (2003) A feedback mechanism between soil moisture distribution and storm tracks. Q J R Meteorol Soc 129:2279-2297

Pal JS, Small EE, Eltahir EAB (2000) Simulation of regional scale water and energy budgets: influence of a new moist physics scheme within RegCM. J Geophys Res 105: 29579-29594

Pal JS, Giorgi F, Bi X, Elguindi N and others (2007) Regional climate modeling for the developing world: the ICTP RegCM3 and RegCNET. Bull Am Meteorol Soc 88: 1395-1409

Parry ML, Canziani OF, Palutikof JP, van der Linden PJ, Hanson CE (eds) (2007) Summary for policymakers. In:

Submitted: April 26, 2011; Accepted: November 30, 2011
Climate Change 2007: Impacts, adaptation and vulnerability. Contribution of Working Group II to the Fourth Assessment Report of the Intergovernmental Panel on Climate Change. Cambridge University Press, Cambridge, p 7-22

Rauscher SA, Seth A, Qian JH, Camargo SJ (2006) Domain choice in an experimental nested modeling prediction system for South America. Theor Appl Climatol 86: 229-246

Rauscher SA, Coppola E, Piani C, Giorgi F (2010) Resolution effects on regional climate model simulations of seasonal precipitation over Europe. Clim Dyn 35:685-711

Reynolds RW, Rayner NA, Smith TM, Stokes DC, Wang W (2002) An improved in situ and satellite SST analysis for climate. J Clim 15:1609-1625

Roeckner E, Bäuml BG, Bonaventura L, Brokopf R and others (2003) The atmospheric general circulation model ECHAM5. I. Model description. Technical Report 349, Max Planck Institute for Meteorology, Hamburg

Seth A, Rauscher SA, Carmago SJ, Qian JH, Pal JS (2007) RegCM3 regional climatologies using reanalysis and ECHAM global model driving fields. Clim Dyn 28: 461-480

Smiatek G, Kunstmann H, Heckl A (2011) High resolution climate change simulations for the Jordan River area. J Geophys Res 16 D16111. doi:10.1029/2010JD015313

Sylla MB, Gaye AT, Pal JS, Jenkins GS, Bi X (2009) High resolution simulations of West African climate using regional climate model (RegCM3) with different lateral boundary conditions. Theor Appl Climatol 98: 293-314

Uppala SM, Allberg K, Simmmons PW, Andrea AJ and others (2005) The ERA-40 re-analysis. Q J R Meteorol Soc 131:2961-3012

> Zakey A, Solmon F, Girogi F (2006) Development and testing of a desert dust module in a regional climate model. Atmos Chem Phys 6:4687-4704

> Zeng X, Zhao M, Dickinson RE (1998) Intercomparison of bulk aerodynamic algorithms for the computation of sea surface fluxes using TOGA COARE and TAO data. J Clim 11:2628-2644

Proofs received from author(s): January 30, 2012 